\title{
Students' perception of a flipped classroom approach to facilitating online project-based learning in marketing research courses
}

\author{
Wen-Ling Shih \\ Cheng Shiu University, Kaohsiung City, Taiwan \\ Chun-Yen Tsai \\ National Sun Yat-sen University, Kaohsiung City, Taiwan
}

\begin{abstract}
This study investigated students' perception of a flipped classroom approach to facilitating online project-based learning (FC-OPBL) in a marketing research course at a technical university. This combined strategy was aimed at improving teaching quality and learning efficiency. Sixty-seven students taking a marketing research course were surveyed. Mixed methods research was adopted along with questionnaire, semi-structured interviews, online learning notes, and online discussions to understand the students' perception of the teaching strategy used during the learning process. Results showed that FC-OPBL may enhance students’ learning effectiveness, learning motivation, and learning interest, as well as encourage diverse development and teamwork. Finally, suggestions are proposed related to flipped classroom research and instruction.
\end{abstract}

\section{Introduction}

Owing to advances in technology and the rise of student-centred learning environments, the flipped classroom has drawn much attention from both researchers and the teaching community, becoming a popular style of teaching (Bergmann \& Sams, 2012; Chen, Wang, Kinshuk, \& Chen, 2014; Howitt \& Pegrum, 2015; Kim, Kim, Khera, \& Getman, 2014; Lai \& Hwang, 2016; Tucker, 2012). Traditional teaching methods centre on the teacher, with students learning passively as information is provided in a single teacher-to-student direction (Flumerfelt \& Green, 2013; Sahin, Cavlazoglu, \& Zeytuncu, 2015). Because all students simultaneously receive information during lectures, teachers cannot attend to students at different levels or with different learning speeds. Flipped classrooms centre on students and encourage class preparation to reserve more time for in-class activities (Goodwin \& Miller, 2013). This approach allows students to interact and cultivate higher-level cognitive skills, and accounts for students at different levels (Bergmann \& Sams, 2012; Chen \& Chen, 2015).

Project-based learning (PBL) is also a student-centred teaching method that aims to cultivate student teamwork, interdisciplinary skills, critical thinking, interpersonal communication, and project management abilities (Helle, Tynjälä, \& Olkinuora, 2006; Powell \& Weenk, 2003). Projects and group learning are used for students to begin working with teammates rather than merely listening and reading abstract concepts so that they can apply these concepts to real-life problems (Fernandes, 2014; Michaelsen, Knight, \& Fink, 2004). Online project-based learning (OPBL) is a popular approach that uses technology to increase the efficiency of PBL (Heo, Lim, \& Kim, 2010; Sendag \& Odabasi, 2009).

Marketing research constitutes an important subject area in business schools. Under normal circumstances, marketing research courses are relatively difficult for students, especially when traditional lecturing is used. To learn marketing research well, students are required to understand certain basic concepts, including basic business knowledge and statistical analysis. Teachers of marketing research have pointed out that in their experience, many students are apathetic and detached from the course content, and they often believe that the subject is difficult to understand and hard to apply in practice (Makienko \& Barnard, 2012).

This study examined students' perception of a flipped classroom approach to facilitating online project-based learning (FC-OPBL) in a marketing research course at a technical university. The curriculum design applied flipped classrooms as the teaching strategy and OPBL as the learning method. From a teacher's perspective, this study proposed a novel teaching model for students to gain professional knowledge, skills, and competencies. Such instructional design may benefit both teachers and students: instructors improve their teaching effectiveness by providing students with opportunities to apply their 
knowledge, and students begin to understand the advantages of developing strong research and data analysis skills. The main research questions were as follows:

1. How do students' perceptions of the combined model align to cognitive, affective, and behavioural learning domains?

2. How do marketing research students perceive a combined flipped classroom and PBL experience?

\section{Literature review}

\section{Flipped classroom}

The flipped classroom is an approach that switches in-class lectures with collaborative hands-on activities and requires students to preview course materials outside of class (Chen et al., 2014; Chen \& Chen, 2015; Lai \& Hwang, 2016). There are multiple terms for flipped classrooms, including flipped learning, reversed instruction, blended learning, and inverted classrooms (Bergmann \& Sams, 2012; Chen et al., 2014). This "flipping" of activities is not limited to lectures and homework. The core concept consists of reversing the thinking behind traditional teaching and using innovative teaching strategies. Flipped classrooms apply emerging technologies and require students to prepare for classes by viewing online videos provided by the teachers (Flumerfelt \& Green, 2013; Sahin et al., 2015). Flipped classrooms thus combine two elements: interactive group learning activities inside the classroom and direct computer-based individual instruction outside the classroom (Bishop \& Verleger, 2013). This practice was later greatly encouraged by the Khan Academy (Chen et al., 2014) and inverted the paradigm of teaching (Goodwin \& Miller, 2013).

Flipped classroom work can be divided into three stages: preclass learning preparation, in-class learning activities, and postclass learning consolidation (Kong, 2014, 2015). For the preclass learning preparation, students engage in autonomous learning using online learning platforms. For the in-class learning activities, the students and the teacher complete participatory learning activities. Teachers and students discuss, debate, and present, simulating the lesson content (Chen et al., 2014; Estes, Ingram, \& Liu, 2014; Tucker, 2012). This active learning strategy aims to improve teaching quality and learning efficiency (Baepler, Walker, \& Driessen, 2014; Demski, 2013; Sparks, 2011). The learning activities during class then deepen and broaden students' understanding. During postclass learning consolidation, students review materials to improve learning outcomes. This allows students to learn outside of classrooms, apply what they have learned in class, work with other students, and receive direct feedback from teachers (Warter-Perez \& Dong, 2012). Redesigning courses after careful examination can improve teaching (Tucker, 2012), assist students in developing active learning habits, increase teacher-student interaction, and provide a friendly learning environment for students at different levels (Bergmann \& Sams, 2012; Keefe, 2007; Kim et al., 2014; Lage, Platt, \& Treglia, 2000).

The flipped classroom emphasises that teachers and students occupy different roles than they have in traditional classrooms. Teachers can take on multiple roles in flipped classrooms such as theme experts, instructional designers, and media developers. Teachers may adopt more active learning strategies, strengthen flipped classroom techniques, and design more interactive learning activities in the classroom, such as problem-solving and situated learning. Encouraging students to take active, rather than passive, roles in their learning is critical to facilitate the success of flipped classrooms (Estes et al., 2014; Montgomery, Hayward, Dunn, Carbonaro, \& Amrhein, 2015). Failing to complete preclass learning preparation may affect in-class discussions and overall learning outcomes. In addition, student-centred learning environments may adopt more active learning strategies in the classroom, such as student speeches, self-evaluations, peer evaluations, and group discussions (Lai \& Hwang, 2016; Zappe, Leicht, Messner, Litzinger, \& Lee, 2009). Moreover, students in flipped classrooms use self-regulated learning to examine and think critically on the teaching materials in postclass learning consolidation, and also actively apply what they have learned in cooperative learning environments in the classroom (Goodwin \& Miller, 2013; Morrison, Ross, Kalman, \& Kemp, 2011; Sun, Wu, \& Lee, 2016; Tucker, 2012).

\section{Principles for designing flipped classroom courses}

Several scholars have proposed principles for flipped classroom course design. Kim et al. (2014) 
proposed a flipped classroom design framework including four dimensions (teaching presence, learner presence, social presence, and cognitive presence) and nine design principles. The four dimensions in Kim et al. (2014) were adopted from the framework of the revised community of inquiry (Garrison, Anderson, \& Archer, 1999). The Flipped Learning Network (2014) developed the four pillars of F-L-I-P (flexible environment, learning culture, intentional content, and professional educator). However, most scholars typically emphasise only teacher and learner dimensions and overlook the importance of group learning and digital learning platforms.

This study adopted the flipped model proposed by Chen et al. (2014), who modified the F-L-I-P structure established by the Flipped Learning Network and Pearson's School Achievement Services. The flipped model was designed to conform to the design principles for flipped classrooms in higher education (Table 1). The flipped model includes flexible environments, a learner-centred approach, intentional content, professional educators, progressive learning networking activities, engaging and effective learning experiences, and diversified and seamless learning platforms. Empirical research results have shown that the flipped model is effective, students are satisfied with courses, attendance rates improve, and students expend more effort on learning. However, results have also shown that some students remain passive, which obstructs the comprehensive implementation of flipped classrooms. This study maintained the seven principles of this flipped model, but made slight modifications to the content of each principle. The model is described in Table 1 .

Table 1

Principles and description of the flipped model (revised from Chen et al., 2014)

\begin{tabular}{|c|c|}
\hline Principles & Description \\
\hline Flexible environments & $\begin{array}{l}\text { Flipped learning allows for multiple learning models. Teachers arrange } \\
\text { concrete learning spaces according to course properties or unit content in } \\
\text { order to support group work, independent research, or learning-by-doing. }\end{array}$ \\
\hline Learner-centred approach & $\begin{array}{l}\text { The classroom culture shifts from educator-centred to learner-centred. } \\
\text { In-class time is used for exploring topics in greater depth and creating } \\
\text { better learning opportunities. Because the knowledge is constructed by the } \\
\text { students themselves, learning becomes more meaningful to them. }\end{array}$ \\
\hline Intentional content & $\begin{array}{l}\text { Educators continually think about how they use the flipped learning model } \\
\text { to help students develop conceptual understanding and procedural fluency. } \\
\text { Educators used intentional content to maximise classroom time in order to } \\
\text { adopt student-centred active learning strategies tailored for each grade } \\
\text { level and subject matter. }\end{array}$ \\
\hline Professional educators & $\begin{array}{l}\text { Teachers' professional roles are more crucial in flipped learning than in } \\
\text { traditional models. Teachers constantly observe students, provide timely } \\
\text { feedback, and evaluate their learning. Teachers reflect upon themselves in } \\
\text { practice to improve teaching, accept constructive criticism, and tolerate } \\
\text { controllable chaos in the classroom. }\end{array}$ \\
\hline $\begin{array}{l}\text { Progressive learning } \\
\text { networking activities }\end{array}$ & $\begin{array}{l}\text { The concept of advanced education is adopted to emphasise individual } \\
\text { instruction and group discussions. Social media and online networks are } \\
\text { used for team learning. }\end{array}$ \\
\hline $\begin{array}{l}\text { Engaging and effective } \\
\text { learning experiences }\end{array}$ & $\begin{array}{l}\text { Teachers track the effectiveness of students' self-learning courses, possess } \\
\text { better teaching skills and strategies, and produce an active learning } \\
\text { environment and attitude. }\end{array}$ \\
\hline $\begin{array}{l}\text { Diversified and seamless } \\
\text { learning platforms }\end{array}$ & $\begin{array}{l}\text { Teaching platforms satisfy individualisation, differentiation, and } \\
\text { personalisation needs to support self-regulated learning activities. }\end{array}$ \\
\hline
\end{tabular}

\section{Online project-based learning (OPBL)}

PBL is a learning strategy based on developing projects in which students plan, implement, and evaluate projects that have real world application beyond the classroom (Domínguez \& Jaime, 2010; Helle et al., 2006; Thomas, 2000). The advantages of PBL include integrating learning and real life, increasing learning motivation, and improving problem-solving skills (Domínguez \& Jaime, 2010); its core concept consists of connecting students' experiences with school life and encouraging their thinking to assist them 
to gain new knowledge (Efstratia, 2014). PBL does not necessarily require the use of technology; however, by taking advantage of Internet technology, PBL can reduce learning costs, improve learning effectiveness, and create more project-based learning opportunities (Heo et al., 2010; Sendag \& Odabasi, 2009).

Several studies on OPBL (Heo et al., 2010; Sendag \& Odabasi, 2009) have used Internet technology to carry out projects, which also enhanced learning effectiveness. The hyperlinks, hypertexts, hypermedia, and databases on the Internet provide students enriching and diverse learning environments outside of the classroom, while emails, online forums, and chat rooms help students communicate and cooperate (Gwen, 2003). Learners have more opportunities to interact with peers and may gain more from project work. Therefore, scholars use information and communication technology in the implementation of PBL (Heo et al., 2010).

\section{The flipped classroom strategy applied in marketing research courses}

Several scholars have applied flipped classroom strategy in marketing or general education. Findlay-Thompson and Mombourquette (2014) applied flipped classrooms to business courses in university to study the requirements and methods for flipped classrooms. Butt (2014) used flipped classrooms and cooperative learning in an actuarial course at an Australian university and found that students' learning effects were significantly greater than those from traditional teaching methods. Kong (2014) used flipped classrooms in a Hong Kong university to improve students' information application and critical thinking skills and found significant results. Literature concerning both flipped classrooms and OPBL is scarce; therefore, this study proposes an innovative integrated model with the intention of providing a useful contribution to the literature.

This study integrated flipped classrooms and PBL to develop a flipped classrooms teaching strategy for a marketing research course at a technical university. The design focus was on breaking down the course content into fitting projects and step-by-step completion of each activity using flipped classroom teaching. At the end of the course, students are expected to have improved their learning effectiveness and developed new skills; they then apply what they learned to complete a report.

The primary learning objective of a marketing research course is to gain an improved understanding of how to design effective questionnaires, as well as to promote the practical value of research among students. To achieve these goals, this study integrated teaching content, project processes, and flipped classroom teaching activities to design a teaching strategy for marketing research. This integral structure produces more effective, efficient, and beneficial instruction.

\section{Methodology}

\section{Participants}

A total of 72 students took part in the marketing research course at a technical university in southern Taiwan. These students were in the sophomore year and majored in digital multimedia design. These students had lower academic achievement and were generally more passive in learning than typical university students in Taiwan. The technical university at which the investigator taught was used as the research site. The marketing research course was a required second-year course for the department of digital multimedia design. The two-credit course met for 2 hours per week for 18 weeks; thus, this study conducted 18 weeks of activities. Two students dropped the course and three students failed; a total of 67 completed the course.

\section{Design}

This study used mixed methods research (Creswell \& Plano Clark, 2011; Kim et al., 2014) to investigate students' perception of the facilitation of online project-based learning by the flipped classroom approach. The FC-OPBL is a novel instructional strategy and can be investigated from different facets of students' perception. Qualitative and quantitative research methods have their advantages and disadvantages, which can be addressed by the use of mixed methods (Creswell \& Plano Clark, 2011). The advantages are cross validation and complementation of research processes. In the case of the embedded experimental mixed 
methods design, the investigator may embed qualitative data to examine the process of an intervention or to explain participants’ perception in the intervention (Creswell \& Plano Clark, 2011).

Creswell and Plano Clark (2011) indicate that the basic procedures of embedded experimental mixed methods design are data collection before intervention, during intervention, and after intervention. As the lecturer of this course, the first author aimed to improve on-site teaching by participating in, reflecting upon, giving feedback to, and modifying on-site work. Before intervention, the investigators interviewed students to design the flipped classroom activities. During intervention, a total of 67 online learning and discussion notes were collected. After intervention, in-depth interviews and questionnaires were conducted. In-depth, semistructured interviews were conducted with 15 participants using purposive sampling. Interviews were held at the end of specific class, at the end of class on the last day of each unit, and at the end of the course, with 45 interviews in total. To maintain the objectivity of the research results, two other experts from related fields were invited to form a research team and platform data and interview results were compared for triangulation to increase the validity of the analysis outcomes.

\section{FC-OPBL model}

As shown in Figure 1, there are three dimensions in the FC-OPBL model: content, OPBL processes, and flipped classroom activities. In terms of the content dimension, courses focused on the concepts and methods behind marketing research, questionnaire design, data collection, sampling methods, concepts of reliability and validity, data processing, statistical analysis, and chart drawing. Among these areas, questionnaire design constitutes a particularly important topic because the quality of the research conclusions depends on the quality of the basic statistics. By contrast, the quality of statistics largely depends on the research design including sampling planning and questionnaires. Designing a good questionnaire poses a challenging task that involves several correlated principles such as the choice of wording, order of sequence, form, and scale (Bove \& Davies, 2009; Makienko \& Bernard, 2012).

With regard to the dimension of OPBL processes, in addition to the assimilation of professional knowledge, the cultivation of students' problem-solving, critical thinking, knowledge integration, information technology, verbal and written communication, and teamwork skills is important. The teacher asked the students to divide themselves into 11 groups of 5 to 7 students each. Each group picked its own topic and completed the project before the end of the semester. The teacher assigned eight study units and divided OPBL into eight steps, with each step having an assignment. The project was completed when all eight steps were completed. Thus, this study combined theory and practice by requesting that students complete all tasks, including organising the teamwork, selecting a topic, designing and distributing questionnaires, inputting data, analysing charts, and completing writing projects.

In terms of the flipped classroom activities dimension, this study incorporated various participatory learning and learning-by-doing activities such as knowledge sharing, contests, brainstorming, group discussions, practical work, and presentations, in order to improve students' learning effectiveness and cultivate diverse skills. The activities were designed based on the principles of the flipped model mentioned above and the content in each unit. Each group was in charge of topic selection, questionnaire design, sampling methods, questionnaire distribution, and any statistical analysis. This study divided flipped classroom work into three stages (Kong, 2014, 2015) and each unit was divided into preclass learning preparation, in-class learning activities, and postclass learning consolidation (Figure 2). For the preclass learning preparation, students engaged in self-study. Students were required to complete learning assignments for each unit on the online learning platform to develop concepts and understand the course content. The self-study was undertaken using the online teaching materials. During in-class learning activities, students engaged in participatory learning. After the teacher lectured on the main points, which focused on the introduction of later activities, various participatory activities were designed according to the unit content, involving students enhancing their studies through active participation. The activities also helped students answer questions, provided opportunities for self-expression, and prompted learners to proactively seek external help. For the postclass learning consolidation, students engaged in review. This activity helped solidify the learning outcomes and continue class discussions. 
Content

OPBL processes

Flipped classroom activities

Weeks 1-3

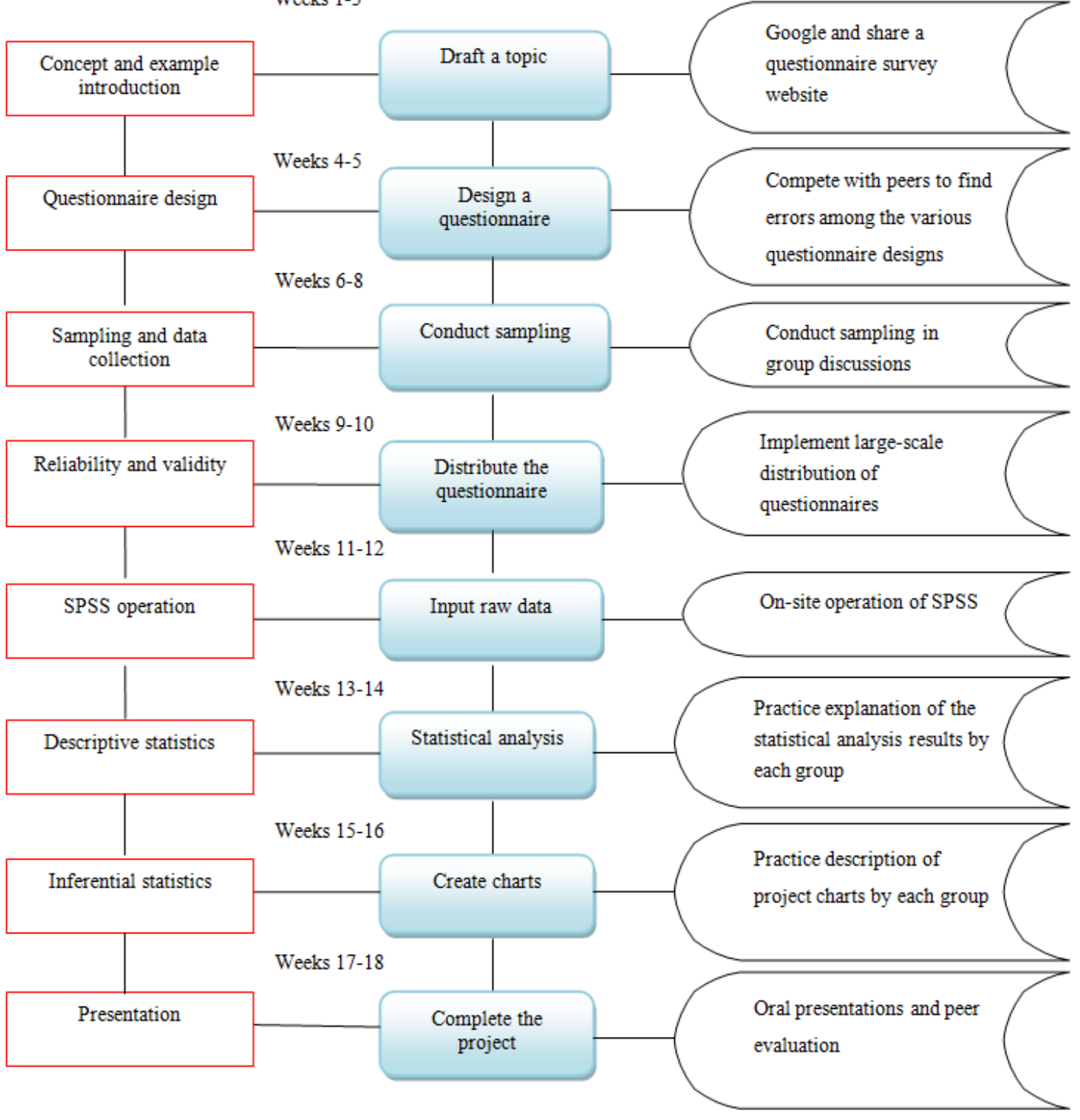

Figure 1. The FC-OPBL teaching strategy applied in the marketing research course 
Preclass/online

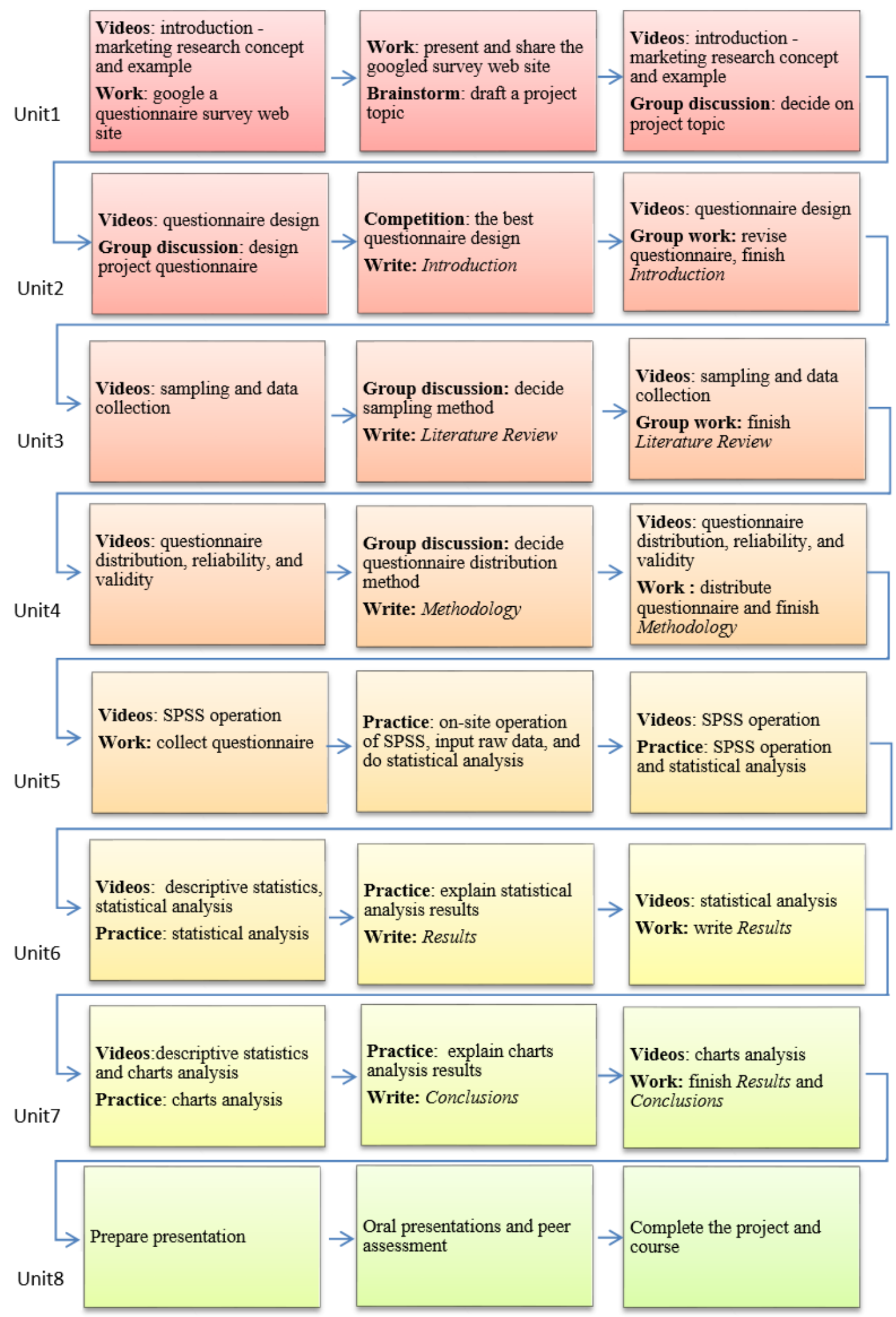

Figure 2. Flipped classroom activities in each unit of OPBL 


\section{Instruments}

The Perceptual Learning Scale

The Perceptual Learning Scale (PLS) referenced the questionnaires used by Warter-Perez and Dong (2012) and Strayer (2007) and was modified based on the flipped classroom activities designed in this study. Regarding content validity, five subscales were created according to the flipped teaching content, namely learning effectiveness, learning motivation, learning interests, cultivation of diversified skills, and facilitation of teamwork. In accordance with the domains of learning (Bloom \& Krathwohl, 1956), these learning outcomes were categorised into three groups: cognition, affection, and skill. Regarding reliability, the Cronbach's $\alpha$ for the total scale was .92 and the Cronbach's $\alpha$ of each subscale ranged between .84 and .94 (Table 2), showing acceptable reliability. A 5-point scale of strongly agree (5), agree (4), neutral (3), disagree (2), and strongly disagree (1) was used for all five scales.

Table 2

Subscales, items, and Cronbach's a coefficients of the PLS

\begin{tabular}{clcc}
\hline Dimensions & \multicolumn{1}{c}{ Subscales } & No. of items & Reliability \\
\hline Cognition & Learning effectiveness & 6 & .91 \\
Affection & Learning motivation & 6 & .94 \\
& Learning interest & 5 & .85 \\
\multirow{2}{*}{ Skill } & Cultivation of diversified skills & 6 & .84 \\
& Facilitation of teamwork & 4 & .84 \\
\hline Total scale & & 27 & .92 \\
\hline
\end{tabular}

Semistructured interview protocol

The flipped classroom interview outline was used to aid the semistructured interviews. The outline included the following questions: (1) How do you feel about the flipped classroom activities for each unit? (2) How do you feel about the flipped classroom self-study? (3) How do you feel about the in-class flipped classroom participatory learning? (4) How do you feel about the postclass review?

\section{The digital learning platform}

The online learning platform included activity announcements, teaching material storage, class organisation, course descriptions, calendars, forums, group areas, notes, assignments, questionnaire surveys, online tests, online meetings, attendance rates, and grade calculation. The records on the platform provided information regarding learners' learning materials and the interaction and communication between members. There were several data in the online learning platform used for the qualitative analyses. The data mainly included the learning notes and group discussions.

\section{Data analysis}

In terms of quantitative data, this study used percentages, means, standard deviation, and related statistical methods for analyses. In terms of qualitative data, the 15 students who were interviewed were numbered I-1 to I-15. Online learning notes were coded as $\mathrm{N}$ - plus seat number, and online discussions were coded as D- plus seat number.

\section{Results}

\section{Students' perception of FC-OPBL in the cognitive dimension}

According to students' self-report of the "learning effectiveness" subscale, the mean of the item "charts can improve learning effectiveness" had the highest agreement among flipped teaching activities $(M=$ 4.03), with $81 \%$ of students agreeing. This was followed by "finding questionnaire errors" $(M=4.00)$, “questionnaire distribution" ( $M=3.95)$, “using computers for practice” $(M=3.92)$, "presentation” $(M=$ 3.78), and "Google search practice” ( $M=3.75)$ (Table 3). 
Table 3

Students' self-report of the "learning effectiveness" subscale $(n=67)$

\begin{tabular}{|c|c|c|c|c|c|c|}
\hline Item & $\begin{array}{c}\text { Strongly } \\
\text { agree }\end{array}$ & Agree & Neutral & Disagree & $\begin{array}{l}\text { Strongly } \\
\text { disagree }\end{array}$ & $M$ \\
\hline $\begin{array}{l}\text { Google search practice can } \\
\text { improve learning effectiveness }\end{array}$ & $\begin{array}{c}11 \\
(17.5 \%)\end{array}$ & $\begin{array}{c}28 \\
(44.4 \%)\end{array}$ & $\begin{array}{c}21 \\
(33.3 \%)\end{array}$ & $\begin{array}{c}3 \\
(4.8 \%)\end{array}$ & $\begin{array}{c}0 \\
(0 \%)\end{array}$ & 3.75 \\
\hline $\begin{array}{l}\text { Finding questionnaire errors can } \\
\text { improve learning effectiveness }\end{array}$ & $\begin{array}{c}13 \\
(20.6 \%)\end{array}$ & $\begin{array}{c}38 \\
(60.3 \%)\end{array}$ & $\begin{array}{c}11 \\
(17.5 \%)\end{array}$ & $\begin{array}{c}1 \\
(1.6 \%)\end{array}$ & $\begin{array}{c}0 \\
(0 \%)\end{array}$ & 4.00 \\
\hline $\begin{array}{l}\text { Questionnaire distribution can } \\
\text { improve learning effectiveness }\end{array}$ & $\begin{array}{c}16 \\
(25.4 \%)\end{array}$ & $\begin{array}{c}30 \\
(47.6 \%)\end{array}$ & $\begin{array}{c}16 \\
(25.4 \%)\end{array}$ & $\begin{array}{c}0 \\
(0 \%)\end{array}$ & $\begin{array}{c}1 \\
(1.6 \%)\end{array}$ & 3.95 \\
\hline $\begin{array}{l}\text { Chart explanation can improve } \\
\text { learning effectiveness }\end{array}$ & $\begin{array}{c}16 \\
(25.4 \%)\end{array}$ & $\begin{array}{c}35 \\
(55.6 \%)\end{array}$ & $\begin{array}{c}11 \\
(17.5 \%)\end{array}$ & $\begin{array}{c}0 \\
(0 \%)\end{array}$ & $\begin{array}{c}1 \\
(1.6 \%)\end{array}$ & 4.03 \\
\hline $\begin{array}{l}\text { Using computers for practice can } \\
\text { improve learning effectiveness }\end{array}$ & $\begin{array}{c}15 \\
(23.8 \%)\end{array}$ & $\begin{array}{c}31 \\
(49.2 \%)\end{array}$ & $\begin{array}{c}15 \\
(23.8 \%)\end{array}$ & $\begin{array}{c}1 \\
(1.6 \%)\end{array}$ & $\begin{array}{c}1 \\
(1.6 \%)\end{array}$ & 3.92 \\
\hline $\begin{array}{l}\text { Presentations can improve } \\
\text { learning effectiveness }\end{array}$ & $\begin{array}{c}15 \\
(23.8 \%)\end{array}$ & $\begin{array}{c}34 \\
(54.0 \%)\end{array}$ & $\begin{array}{c}12 \\
(19.0 \%)\end{array}$ & $\begin{array}{c}1 \\
(1.6 \%)\end{array}$ & $\begin{array}{c}1 \\
(1.6 \%)\end{array}$ & 3.78 \\
\hline
\end{tabular}

\section{Students' perception of FC-OPBL in the affective dimension}

The results showed that the students' perceptions regarding FC-OPBL had a medium agreement for each item (Table 4), indicating that students perceived that FC-OPBL might effectively enhance learning motivation. Of the teaching activities, "finding questionnaire errors can improve learning motivation" had the highest agreement $(M=3.98)$, with $69.8 \%$ student agreement. This was followed by "presentations" $(\mathrm{M}=3.97)$, "Google search practice” and "questionnaire distribution” $(M=3.83)$, "chart explanation” $(M$ = 3.81), and "using computers for practice" $(M=3.78)$.

Table 4

Results of the "learning motivation" subscale $(n=67)$

\begin{tabular}{lcccccc}
\hline Item & $\begin{array}{c}\text { Strongly } \\
\text { agree }\end{array}$ & Agree & Neutral & Disagree & $\begin{array}{c}\text { Strongly } \\
\text { disagree }\end{array}$ & $M$ \\
\hline Google search practice can improve & 10 & 33 & 19 & 1 & 0 & 3.83 \\
learning motivation & $(15.9 \%)$ & $(52.4 \%)$ & $(30.2 \%)$ & $(1.6 \%)$ & $(0 \%)$ & 0 \\
Finding questionnaire errors can & 20 & 24 & 17 & 2 & 0 & 3.98 \\
improve learning motivation & $(31.7 \%)$ & $(38.1 \%)$ & $(27 \%)$ & $(3.2 \%)$ & $(0 \%)$ & \\
Questionnaire distribution can & 16 & 22 & 23 & 2 & 0 & 3.83 \\
improve learning motivation & $(25.4 \%)$ & $(34.9 \%)$ & $(36.5 \%)$ & $(3.2 \%)$ & $(0 \%)$ & \\
Chart explanation can improve & 12 & 31 & 17 & 2 & 1 & 3.81 \\
learning motivation & $(19 \%)$ & $(49.2 \%)$ & $(27 \%)$ & $(3.2 \%)$ & $(1.6 \%)$ & \\
Using computers for practice can & 11 & 30 & 20 & 1 & 1 & 3.78 \\
improve learning motivation & $(17.5 \%)$ & $(47.6 \%)$ & $(31.7 \%)$ & $(1.6 \%)$ & $(1.6 \%)$ & 3.97 \\
Presentations can improve learning & 13 & 32 & 14 & 3 & 1 & $3.6 \%)$ \\
motivation & $(20.6 \%)$ & $(50.8 \%)$ & $(22.2 \%)$ & $(4.8 \%)$ & $(1.6 \%)$ & \\
\hline
\end{tabular}

In terms of enhancing learning interest (Table 5), "FC-OPBL can improve interest in knowledge construction" had the highest agreement $(M=4.06)$, followed by "be a suitable teaching strategy" $(M=$ 3.84), "improving interest in exploring topics" $(M=3.81)$, “improving subject interest” $(M=3.75)$, and “improving interest in class" $(\mathrm{M}=3.68)$. 
Table 5

Mean and SD of the "learning interest" subscale $(n=67)$

\begin{tabular}{lcc}
\hline \multicolumn{1}{c}{ Item } & $M$ & $S D$ \\
\hline FC-OPBL can improve interest in knowledge construction & 4.06 & .84 \\
FC-OPBL can improve subject interest & 3.75 & .82 \\
FC-OPBL can improve interest in exploring topics & 3.81 & .74 \\
FC-OPBL can improve interest in class & 3.68 & .64 \\
FC-OPBL can be a suitable teaching strategy & 3.84 & .68 \\
\hline
\end{tabular}

Students' perception of FC-OPBL in the skill dimension

Regarding the perception of using FC-OPBL to cultivate diverse skills (Table 6), "FC-OPBL can cultivate communication skills" had the highest agreement $(M=4.21)$, followed by "information technology skills" ( $M=4.08)$, "problem-solving skills" $(M=4.03)$, "critical thinking skills" $(M=4.02)$, "knowledge integration skills" $(M=3.94)$, and "self-regulation skills" $(M=3.79)$. Regarding the perception of enhancing teamwork, "FC-OPBL can enhance interaction skills" had the highest agreement $(M=4.05)$, followed by "improving cooperative abilities" $(M=4.03)$, "developing team spirit" $(M=3.98)$, and "completing projects together" $(M=3.70)$.

Table 6

Mean and SD of the skills scale $(n=67)$

\begin{tabular}{lcc|lll}
\hline \multicolumn{1}{c|}{ Cultivation of Skills } & & \multicolumn{3}{c}{ Enhancement of Teamwork } \\
\hline Item & $M$ & $S D$ & Item & $M$ & $S D$ \\
\hline $\begin{array}{l}\text { FC-OPBL can cultivate } \\
\text { problem-solving skills }\end{array}$ & 4.03 & .84 & $\begin{array}{l}\text { FC-OPBL can enhance interaction } \\
\text { skills }\end{array}$ & 4.05 & .79 \\
$\begin{array}{l}\text { FC-OPBL can cultivate critical } \\
\text { thinking skills }\end{array}$ & 4.02 & .71 & $\begin{array}{l}\text { FC-OPBL can enhance } \\
\text { cooperative abilities }\end{array}$ & 4.03 & .78 \\
$\begin{array}{l}\text { FC-OPBL can cultivate knowledge } \\
\text { integration skills }\end{array}$ & 3.94 & .69 & FC-OPBL can develop team spirit & 3.98 & .56 \\
$\begin{array}{l}\text { FC-OPBL can cultivate information } \\
\text { technology skills }\end{array}$ & 4.08 & .81 & $\begin{array}{l}\text { FC-OPBL allows students to } \\
\text { complete projects together }\end{array}$ & 3.70 & .89 \\
$\begin{array}{l}\text { FC-OPBL can cultivate } \\
\text { communication skills }\end{array}$ & 4.21 & .46 & & & \\
$\begin{array}{l}\text { FC-OPBL can cultivate self-regulation } \\
\text { skills }\end{array}$ & 3.79 & .77 & & & \\
\hline
\end{tabular}

\section{Students' perception of the combined flipped classroom and PBL experience}

The flipped model proposed by Chen et al. (2014) was adopted in this study to design the learning strategies. The flipped model includes flexible environments, a learner-centred approach, intentional content, professional educators, progressive learning networking activities, engaging and effective learning experiences, and diversified and seamless learning platforms. The students' perception of the combined flipped classroom and PBL experience was discussed according to the outline of the flipped model.

Flexible environments: Learning with multiple vehicles

The flipped classroom engages students in the learning process through the use of flexible environments such as web-based environments and mobile environments in preclass and postclass preparation, and inquiry-based classrooms for in-class participation. The teacher used an online learning platform to structure students' self-learning, employing the general classroom environment to carry out students' participatory activities, team work, and group discussions, and using computer lab teaching SPSS (a statistics software program) for students to practice learning-by-doing. The flexible environments provide multiple vehicles for learning and increased opportunity for learning-by-doing.

At first I thought this was a boring class, but the interesting teaching method attracted my attention. It was more engaging and unique than traditional classes. In class, we interacted more and class became more interesting, but we spent more time watching videos and preparing for class at home. (I-10) 
I can learn by using the platform and the Internet, and from teachers or classmates. Because I watched the videos before class, I could easily understand the teacher's lecture. The SPSS practices are also helpful for understanding statistical analysis concepts. (N-25)

\section{Learner-centred approach: Cultivation of active learning}

The teacher designed various flipped classroom activities including brainstorming, competition, group discussion, practice, and presentation. By completing these activities, students could improve their learning opportunities and actively construct knowledge. To complete the entire project, students had to learn and cooperate actively; at the same time, they could cultivate diversified skills such as problem-solving, critical thinking, knowledge integration, and communication through the learning process. Students’ cooperative abilities were also developed through teamwork. Although this course increased the pressure of homework, I learned a lot from presentations,
questionnaire surveys, conclusions and analysis, and peer observations. (N-29)

This class was exhausting. We had to hand out questionnaires and even conduct statistical analysis; however, the final presentation outcomes were amazing and even praised by the teacher, which boosted my sense of achievement. (I-09)

I was not interested in taking a business course, but afterward I found that the course was well-organised, and learning-by-doing works were much more effective than lectures. I also learned a lot from discussing assignments and reports. My mind was always filled with new knowledge after class. (I-07)

Intentional content: In-class and out-of-class teaching material classification

Initially, all course materials were put on the platform, and students had to do the preview out of class. In class, the teacher's lecture consisted of delivering advanced materials, answering questions, and guiding students in the in-depth discussion. However, some students responded that there was too much learning material, and in response the teacher divided it into in-class and out-of-class materials. Out-of-class materials were placed in the self-learning area, whereas in-class materials were taught directly.

If the materials on the online platform are too numerous, varied, or difficult, I may be reluctant to prepare for class. (D-36)

Although the learning platform is rich in resources, the excessive amount of learning materials lowers students' willingness to read. (D-04)

Professional educators: Observing, evaluating, feedback, and improving

The teacher had to observe, evaluate students' learning effectiveness, and give feedback in order to improve teaching effectiveness. The teacher also had to play the role of professional educator and facilitator of students' inquiry and group cooperation. The interview results showed that traditional lectures have trained students to be passive learners. If students do not preview the material, then the teacher had to explain the content during class. This negates the effect of the flipped classroom. In order to successfully flip the classroom, students have to be in the habit of previewing materials, thereby creating more time during class for activities. Hence, self-study before class is important. The teacher communicated more with students to change their passive attitudes so that they were willing to study. However, changing students' habits is difficult. Consequently, strategies and incentives can be prepared and examined. Methods for inspection include online or paper tests.

To be blunt, students are all passive; unless they need to hand in assignments or study for tests, they will only log into the platform for fear of failing the course. (I-04)

Honestly, sometimes I might fail to finish the learning materials out of class. Therefore, I might not interact with peers or the teacher for in-depth discussions in the class. (N-05)

Learning how to organise data and express ourselves in class is a good thing, but students in Taiwan do not speak much in class, compared to those in the United States. If this model are implemented in the United States, it might be more effective. (D-25) 
In the learning process, most of the groups cooperated well and discovered their individual members' strengths and weaknesses, although there were a few groups that faced collaboration problems. For these groups, the teacher had to deal with the problems promptly to enable the students to move on.

Flipped classrooms depend on how well students work together; it will not work if the students do not pair well. (I-03)

People who get along do not necessarily make good team members. I learned how to quickly deal with situations where members did not cooperate well. (N-43)

Working in teams has its pros and cons. It can increase interaction among classmates, but some people are selfish and leave the work to others. $(\mathrm{N}-11)$

Though sometimes the teams encountered conflict, I learned to accept the opinions of others. (N-57)

Progressive learning networking activities: Individual learning and group cooperation

Networking activities serve as tools of knowledge sharing and group discussions. Participatory activity design integrates theory and practice so that learned materials can be put to use. Students were divided into groups to stimulate peer interaction and inspiration in order to ensure assignment delivery.

It is a great experience for learning to work as a team and divide work among members. (D-42)

Classmates helped me become familiar with the subject. (D-19)

Dividing students into groups allows them to discover their talents; for example, some people are good at oral presentations whereas others are better at organising data. (I-05)

The presentations in each group showcased their potential. We were among the last five groups to give presentations, which was a relief but also nerve racking. We were able to see the other groups' mistakes, and learn from them to improve our presentation. However, seeing how well classmates did was stressful and we were afraid that we would not surpass that. (D-69)

Engaging and effective learning experiences: Producing an active learning environment and attitude The teacher used learning-by-doing, hands-on projects, and experiential learning to support individual learning, and used networking activities to support group work. Students learned through practicing, undertaking projects, discussion, and solving problems. They exerted great effort during the process and gained a feeling of accomplishment.

Distributing questionnaires was a good way to learn; it motivated me. I have never had an experience like this before; it gave me the courage to ask people to fill out the questionnaires. Although I faced many rejections, this was a rare opportunity for students, so I think it was an unforgettable experience. (N-44)

We barely slept for this final report. We wanted it to be perfect for the presentation, and the teacher's positive comment on the results was satisfying. $(\mathrm{N}-54)$

The interview results showed that the most difficult part of the statistical analysis was not the operation of SPSS, but explaining the data. Therefore, students operated the software in the computer lab on six occasions, and the teacher provided charts and tables as examples. Students in each group then explained and analysed their statistical results and gave presentations. Students believed that many questions could be solved during operation, and the teacher could immediately correct errors.

We got to know whether our statistical analysis was correct in computer class, and errors would be corrected by the teacher; in this way, students learned fast. (I-55) 
The competition of the best questionnaire design was interesting; it was motivating and helped us understand what could be improved. (I-02)

I liked this teaching method; it improved my presentation-making abilities. (D-51)

Diversified and seamless learning platforms: Graded learning materials to support self-learning The online learning platform provided basic and advanced learning materials for learners at different levels to support self-learning activities. It also provided interactive and communication functions to support group learning. The teacher could track students' learning situations by assessing their records. However, this study found that traditional lecture materials did not attract students' interest; students preferred viewing short films to the video of the teacher's lecture.

Learning materials were divided into basic and advanced levels; this made it easier to learn. (D-38)

Videos need to be more interesting, I prefer watching short films to listening to the teacher's lecture. $(\mathrm{N}-23)$

\section{Discussion}

\section{Students' perception of the cognitive dimension}

Regarding the students' perception of the cognitive dimension, FC-OPBL may enhance learning effectiveness. These results are consistent with the findings reported by Roach (2014). At the beginning of the course, project completion was divided into eight phases that were completed step-by-step to ensure completion of the project. Moreover, students were divided into groups to stimulate peer interaction and inspiration in order to ensure assignment delivery. Work during each phase could be observed by others as it was being completed. As a result, students gained knowledge and also encouraged themselves to work harder. Regarding the students' perception of teaching activities, chart explanation enhanced learning effectiveness the most $(M=4.03)$ with $81 \%$ agreement from students. Interviews showed that the most difficult part of the statistical analysis was not the operation of SPSS, but explaining the data. Therefore, students operated the software in the computer lab on six occasions, and the teacher provided charts and tables as examples. Then, students explained and analysed their statistical results and gave presentations one group at a time. Regarding this chart explanation activity, students believed many questions could be solved during operation, and the teacher could immediately fix errors. Thus, students perceived that this activity enhanced learning effectiveness the most, followed by finding errors in the questionnaire $(M=4.00)$ with $80.9 \%$ agreement from students. The reason for this was that when students competed with each other to be the first to discover errors, they could immediately learn about creating questionnaires and discover the questionnaire errors of each group. The other activities received a minimum $61.9 \%(M=3.75)$ agreement rate, indicating that these activities may also enhance learning effectiveness.

\section{Students' perception of the affective dimension}

FC-OPBL may enhance learning motivation and improve learning interest. These results are consistent with the findings of Butt (2014) and Findlay-Thompson and Mombourquette (2014). Hands-on activities may be one of the reasons that learning interest was enhanced. Finding questionnaire errors inspired learning motivation the most $(M=3.98)$ because students engaged in the contests and interesting activity designs, allowing them to compete against, learn from, and work together with each other and build knowledge independently. Students became motivated to find problems first and, therefore, work harder, and were more concentrated on learning. This was followed by presentations $(M=3.97)$, which were given orally over two weeks at the end of the semester. For peer evaluations, when each group was presenting, other groups learned and noted strengths and weaknesses, thus spurring learning motivation. Regarding improving learning interest, FC-OPBL can increase knowledge construction $(M=4.06)$, and is also a suitable teaching strategy $(M=3.84)$, and thus may enhance learning interests. However, the interview results showed that some students logged into the platform only to deliver assignments, observe others' assignments, or use other resources without spending much time reading the teaching materials. Hence, this aspect requires further investigation. 


\section{Students' perception of the skills dimension}

The students perceived that FC-OPBL may cultivate diverse skills such as problem-solving, critical thinking, knowledge integration, and communication skills, and also facilitate teamwork. These results are consistent with the findings of Kong (2014). Group presentations in class bring students together as a team and inspire autonomous learning outside class. Dividing students into groups may strengthen teamwork and communication skills; however, it may also result in an uneven division of work. Therefore, properly dividing tasks is important. Most students supported the implementation of FC-OPBL. They believed that this approach could fulfil student-centred autonomous learning, facilitate diversified development, cultivate active learning, and encourage teamwork.

\section{Students' perception of flipped classroom strategy}

In traditional classrooms in Taiwan, teachers often use lecture strategy in classrooms. Hence, students may not have to prepare anything for class. In this study, students perceived that the flexible environments in the flipped classroom provided them with multiple learning vehicles and opportunities for learning-by-doing. For the learner-centred approach, the students in this study expressed that they learned a lot from the learner-centred activities. Through the use of project-based learning, students could complete their projects step-by-step with guidance. Students' shift from passive to active learning constitutes the key to a successful flipped class (Estes et al., 2014). For the intentional content, students expressed the belief that the materials on the online platform were too numerous and varied, and they felt reluctant to undertake preclass preparation. It may be that an excessive amount of teaching materials causes an excessive cognitive load.

Teachers' professional roles are more crucial in flipped learning and students need to be guided into the correct perspectives in order to increase their willingness to cooperate. This study found that some students were used to being passive learners and were unable to switch to active learning for in-class activities. It may be that Taiwanese students are typically more passive and afraid to voice their opinions in class because they are used to the traditional lecture approach. Instructors may explain the purpose of the flipped classroom to students and convey to them that they should be responsible for their own learning (Baepler et al., 2014; Findlay-Thompson \& Mombourquette, 2014). This study also found that some students may not preview materials during preclass preparation because they are accustomed to traditional teaching methods. Chen et al. (2014) and Findlay-Thompson and Mombourquette (2014) also identified the same situation and remarked that students' workloads are heavier due to homework outside of the classroom. This may pose a challenge to implementing flipped classrooms (Chen \& Chen, 2015). In this study, students perceived the advantage of group discussion but indicated that some difficulties occurred during cooperative learning of in-class learning activities.

For progressive learning networking activities, online discussions during the postclass activities can also bring students closer to the teacher and their classmates and encourage them to participate for team learning. Findlay-Thompson and Mombourquette (2014) also found that participatory activities during class provide students with opportunities to be involved in-class activities that can improve their practical competencies. For engaging and effective learning experiences, hands-on activities and in-class cooperative learning can help strengthen team cooperation (Chen \& Chen, 2015; Chen et al., 2014). However, the prevalence of the lecture approach results in hands-on activities being uncommon in traditional classrooms in Taiwan. In this study, students engaged in in-class and postclass activities. They responded to the different learning approach and were glad to participate in the hands-on activities. For a diversified and seamless learning platform, students' preexisting learning behaviours and interests should be taken into consideration when preparing online teaching materials (Butt, 2014). Well-organized platforms would satisfy adaptive learning and support self-regulated learning activities.

\section{Conclusions and suggestions}

To date, no sufficient study base has been established that indicates exactly how effectively flipped classrooms work (Goodwin \& Miller, 2013). This study used mixed methods research to investigate the perceived effectiveness of FC-OPBL from the standpoint of students' cognitive, affective, and skilled learning. Qualitative and quantitative analyses were implemented. The following conclusions and suggestions are proposed based on the research results. 
In the cognitive dimension, students perceived that FC-OPBL may improve learning effectiveness. Each group learned to design and distribute questionnaires, and also learned basic SPSS skills, statistical analysis, and chart drawing. They learned how to complete a project and present the results orally. In the affective dimension, FC-OPBL may enhance learning motivation and learning interests. Students engaged in contests and interesting activities; they competed against, learned from, and worked with others during projects and built knowledge independently. FC-OPBL also motivated them to learn, enhanced knowledge construction, and increased their interest in academic subjects and topics. Thus, FC-OPBL is a suitable teaching strategy. In the skills dimension, FC-OPBL may cultivate diversified skills such as problem-solving, critical thinking, knowledge integration, information technology, and communication skills. It may also facilitate teamwork, increase peer interaction and cooperative abilities, develop team spirit, and encourage students to complete a project together.

The following suggestions are proposed for the preclass stage of flipped classrooms: (1) Grade e-learning materials: Teachers aim to present knowledge to students. However, uploading all teaching materials to the online learning platform may not take into account the differences between students. The teaching materials may be divided into fundamental materials and advanced materials in consideration of students being at different levels or to provide scaffolding to support learners (Chen \& Chen, 2015; Montgomery et al., 2014) and to guide self-regulated behaviours (Lai \& Hwang, 2016; Sun et al., 2016). (2) Encourage students to solve problems online: Teachers may encourage students to ask any questions on the platform during the self-study stage for other students to answer (Findlay-Thompson \& Mombourquette, 2014; Kim et al., 2014). Thus, students' questions are answered and the teacher can understand what problems students, enabling them to provide detailed answers during in-class activities. Students with the same questions can also reference the online discussion to find answers.

The following suggestions are proposed for the in-class activities of flipped classrooms:

(1) Examine self-study effectiveness: Because students may not be familiar with flipped classroom strategies and struggle to keep up, formative assessments can help teachers understand students' situations.

(2) Design classroom activities: In-class activities aim to provide more in-depth learning and cultivate higher level cognitive skills and other competencies (Kim et al., 2014). To achieve the learning objectives, in-class activities may be designed based on learning theory so that students can gain knowledge and skills through participating in learning.

(3) Conduct social learning: Explanations from peers are sometimes easier to understand than those from a teacher. This may be because students may not feel embarrassed by asking detailed or repeated questions when interacting with their peers (Kim et al., 2014).

The following suggestion is proposed for the postclass stage of flipped classrooms. Respond to learning notes: Teachers may respond, encourage, or provide opinions to students' learning notes. This form of one-on-one interaction allows students to feel that the teacher is concerned about each student.

Several suggestions are made for future work on flipped classroom strategy. To improve the effectiveness of flipped classrooms, future studies may begin by refining teaching materials to attract students. Teaching materials may be divided into several levels to enable students to learn according to their abilities. The effects of adaptive materials in flipped classrooms on students' learning outcome are suggested for investigation. Additionally, a successful flipped classroom requires teachers and students to change their ways of thinking. In a flipped classroom, teachers may raise questions and give clues to support the development of higher-order thinking skills (Findlay-Thompson \& Mombourquette, 2014; Kong, 2015). Enhancing teachers' and students' flipping skills when engaged in peer interactions is important. Moreover, successful flipping depends on synergy between teachers and students, and necessitates constant encouragement and guidance. Students must change their passive learning habits and actively participate. The effect of self-regulation in flipped classrooms on students' learning outcome is a suggested topic for future study (Lai \& Hwang, 2016). 


\section{References}

Baepler, P., Walker, J. D., \& Driessen, M. (2014). It's not about seat time: Blending, flipping, and efficiency in active learning classrooms. Computers \& Education, 78, 227-236. https://doi.org/10.1016/j.compedu.2014.06.006

Bergmann, J., \& Sams, A. (2012). Flip your classroom: Reach every student in every class every day. Washington, DC: ISTE.

Bishop, J., \& Verlezer, M. (2013). Testing the flipped classroom with model-eliciting activities and video lectures in a mid-level undergraduate engineering course. Paper presented in Frontiers in Education Conference, 2013 IEEE. Oklahoma, OK.

Bloom, B. S., \& Krathwohl, D. R. (1956). Taxonomy of educational objectives: The classification of educational goals, by a committee of college and university examiners. Handbook I: Cognitive domain. New York, NY: Longmans, Green.

Bove, L. L., \& Davies, W. M. (2009). A case study of teaching marketing research using client-sponsored projects. Journal of Marketing Education, 31(3), 230-239. https://doi.org/10.1177/0273475309344999

Butt, A. (2014). Student views on the use of a flipped classroom approach: Evidence from Australia. Business Education and Accreditation, 6(1), 33-43.

Chen, L., \& Chen, T. L. (2015). Students' perspectives of using cooperative learning in a flipped statistics classroom. Australasian Journal of Educational Technology, 31(6), 621-640. https://doi.org/10.14742/ajet.1876

Chen, Y. L., Wang, Y. P., Kinshuk, \& Chen, N. S. (2014). Is FLIP enough? Or should we use the FLIPPED model instead? Computers \& Education, 79, 16-27. https://doi.org/10.1016/j.compedu.2014.07.004

Creswell, J. W., \& Plano Clark, V. (2011). Designing and conducting mixed methods research (2nd ed.). Thousand Oaks, CA: Sage.

Demski, J. (2013). 6 Expert tips for flipping the classroom. Retrieved from http://campustechnology.com/articles/2013/01/23/6-expert-tips-for-flipping-the-classroom.aspx

Domínguez, C., \& Jaime, A. (2010). Database design learning: A project-based approach organized through a course management system. Computers \& Education, 55(3), 1312-1320. https://doi.org/10.1016/j.compedu.2010.06.001

Efstratia, D. (2014). Experiential education through project based learning. Procedia - Social and Behavioral Sciences, 152, 1256 - 1260. https://doi.org/10.1016/j.sbspro.2014.09.362

Estes, M. D., Ingram, R., \& Liu, J. C. (2014). A review of flipped classroom research, practice, and technologies. Retrieved from https://www.hetl.org/feature-articles/a-reviewof-flipped-classroom-research-practice-and-technologies/

Fernandes, S. R. G. (2014). Preparing graduates for professional practice: Findings from a case study of project-based learning (PBL). Procedia - Social and Behavioral Sciences, 139, 219-226. https://doi.org/10.1016/j.sbspro.2014.08.064

Findlay-Thompson, S., \& Mombourquette, P. (2014). Evaluation of a flipped classroom in an undergraduate business course. Business Education and Accreditation, 6(1), 63-71.

Flipped Learning Network. (2014). The four pillars of F-L-I-P. Retrieved from http://flippedlearning.org/cms/lib07/VA01923112/Centricity/Domain/46/FLIP_handout_FNL_Web.pdf

Flumerfelt, S., \& Green, G. (2013). Using lean in the flipped classroom for at risk students. Educational Technology \& Society, 16(1), 356-366.

Garrison, D. R., Anderson, T., \& Archer, W. (1999). Critical inquiry in a text-based environment: Computer conferencing in higher education. The Internet and Higher Education, 2(2-3), 87-105. https://doi.org/10.1016/S1096-7516(00)00016-6

Goodwin, B., \& Miller, K. (2013). Evidence on flipped classrooms is still coming in. Educational Leadership, 70(6), 78-80.

Gwen, S. (2003). Project-based learning-a primer. Technology \& Learning, 23(6), 20-27.

Helle, L., Tynjälä, P., \& Olkinuora, E. (2006). Project-based learning in post-secondary education theory, practice and rubber sling shots. Higher Education, 51(2), 287-314. https://doi.org/10.1007/s10734-004-6386-5

Heo, H., Lim, K. Y., \& Kim, Y. (2010). Exploratory study on the patterns of online interaction and knowledge co-construction in project-based learning. Computers \& Education, 55(3), 1383-1392. https://doi.org/10.1016/j.compedu.2010.06.012

Howitt, C, \& Pegrum, M. (2015). Implementing a flipped classroom approach in postgraduate education: 
An unexpected journey into pedagogical redesign. Australasian Journal of Educational Technology, 31(4), 458-469.

Keefe, J. (2007). What is personalization? Phi Delta Kappan, 89(3), 217-223.

Kim, M. K., Kim, S. M., Khera, O., \& Getman, J. (2014). The experience of three flipped classrooms in an urban university: An exploration of design principles. The Internet and Higher Education, 22, 37-50. https://doi.org/10.1016/j.iheduc.2014.04.003

Kong, S. C. (2014). Developing information literacy and critical thinking skills through domain knowledge learning in digital classroom: An experience of practicing flipped classroom strategy. Computers \& Education, 78, 160-173. https://doi.org/10.1016/j.compedu.2014.05.009

Kong, S. C. (2015). An experience of a three-year study on the development of critical thinking skills in flipped secondary classrooms with pedagogical and technological support. Computers \& Education, 89, 16-31. https://doi.org/10.1016/j.compedu.2015.08.017

Lage, M. J., Platt, G. J., \& Treglia, M. (2000). Inverting the classroom: A gateway to creating an inclusive learning environment. The Journal of Economic Education, 31(1), 30-43.

Lai, C. L., \& Hwang, G. J. (2016). A self-regulated flipped classroom approach to improving students’ learning performance in a mathematics course. Computers \& Education, 100, 126-140. https://doi.org/10.1016/j.compedu.2016.05.006

Makienko, I., \& Bernard, E. K. (2012). Teaching applied value of marketing research: A questionnaire design project. The International Journal of Management Education, 10(2), 139-145. https://doi.org/10.1016/j.ijme.2012.03.004

Michaelsen, L. K., Knight, A. B., \& Fink, D. L. (2004). Team-based learning: A transformative use of small groups. Westport, CT: Praeger.

Montgomery, A. P., Hayward, D. V., Dunn, W., Carbonaro, M., \& Amrhein, C. G. (2015). Blending for student engagement: Lessons learned for MOOCs and beyond. Australasian Journal of Educational Technology, 31(6), 657-670. https://doi.org/10.14742/ajet.1869

Morrison, G. R., Ross, S. M., Kalman, H., \& Kemp, J. E. (2011). Designing effective instruction (6th ed.). Hoboken, NJ: John Wiley \& Sons.

Powell, P., \& Weenk, W. (2003). Project-led engineering education. Utrecht: Lemma Publishers.

Roach, T. (2014). Student perceptions toward flipped learning: New methods to increase interaction and active learning in economics. International Review of Economics Education, 17, 74-84. https://doi.org/10.1016/j.iree.2014.08.003

Sahin A., Cavlazoglu, B., \& Zeytuncu, Y. E. (2015). Flipping a college calculus course: A case study. Educational Technology \& Society, 18(3), 142-152.

Sendag, S., \& Odabasi, H. F. (2009). Effects of an online problem based learning course on content knowledge acquisition and critical thinking skills. Computers \& Education, 53(1), 132-141. https://doi.org/10.1016/j.compedu.2009.01.008

Sparks, S. D. (2011). Schools "flip" for lesson model promoted by Khan Academy. Education Week, 31(5), 1-14.

Strayer, J. F. (2007). The effects of the classroom flip on the learning environment: A comparison of learning activity in a traditional classroom and a flip classroom that used an intelligent tutoring system (Doctoral dissertation). The Ohio State University, Columbus, OH.

Sun, J. C. Y., Wu, Y. T., \& Lee, W. I. (2016). The effect of the flipped classroom approach to OpenCourseWare instruction on students' self-regulation. British Journal of Educational Technology, online first. https://doi.org/10.1111/bjet.12444

Thomas, J. W. (2000). A review of research on project-based learning. Novato, CA: The Buck Institute for Education.

Tucker, B. (2012). The flipped classroom: Online instruction at home frees class time for learning. Education Next, 12(1), 82-83.

Warter-Perez, N., \& Dong, J. (2012, April). Flipping the classroom: How to embed inquiry and design projects into a digital engineering lecture. Paper presented at the 2012 ASEE PSW Section Conference. San Luis Obispo, CA.

Zappe, S., Leicht, R., Messner, J., Litzinger, T., \& Lee, H. (2009). "Flipping" the classroom to explore active learning in a large undergraduate course. Paper presented at the 2009 American Society for Engineering Education Annual Conference and Exhibition. New Orleans, LA. 
Corresponding author: Chun-Yen Tsai, ctsai@mail.nsysu.edu.tw

Australasian Journal of Educational Technology (c) 2017.

Please cite as: Shih, W. L, \& Tsai, C. Y. (2017). Students’ perception of a flipped classroom approach to facilitating online project-based learning in marketing research courses. Australasian Journal of Educational Technology, 33(5), 32-49. https://doi.org/10.14742/ajet.2884 